\title{
ARTICLE
}

\section{Abundant DNA 6mA methylation during early embryogenesis of zebrafish and pig}

Jianzhao Liu ${ }^{1, \star}$, Yuanxiang Zhu ${ }^{2, \star}$, Guan-Zheng Luo ${ }^{1, \star}$, Xinxia Wang ${ }^{1,3, \star}$, Yanan Yue ${ }^{1}$, Xiaona Wang ${ }^{2}$, Xin Zong $^{3}$, Kai Chen ${ }^{1}$, Hang Yin ${ }^{1}$, Ye Fu', Dali Han ${ }^{1}$, Yizhen Wang ${ }^{3}$, Dahua Chen ${ }^{2} \&$ Chuan $\mathrm{He}^{1}$

DNA $N^{6}$-methyldeoxyadenosine $(6 \mathrm{~mA})$ is a well-known prokaryotic DNA modification that has been shown to exist and play epigenetic roles in eukaryotic DNA. Here we report that $6 \mathrm{~mA}$ accumulates up to $\sim 0.1-0.2 \%$ of total deoxyadenosine during early embryogenesis of vertebrates, but diminishes to the background level with the progression of the embryo development. During this process a large fraction of $6 \mathrm{mAs}$ locate in repetitive regions of the genome.

\footnotetext{
${ }^{1}$ Department of Chemistry, Department of Biochemistry and Molecular Biology, Institute for Biophysical Dynamics, Howard Hughes Medical Institute, The University of Chicago, 929 East 57th Street, Chicago, Illinois 60637, USA. ${ }^{2}$ State Key Laboratory of Reproductive Biology, Institute of Zoology, Chinese Academy of Sciences, Beijing 100101, China. ${ }^{3}$ Key Laboratory of Animal Nutrition and Feed Sciences, Ministry of Agriculture, College of Animal Sciences, Zhejiang University, No. 866 Yuhangtang Road, Hangzhou, Zhejiang 310058, China. * These authors contributed equally to this work. Correspondence and requests for materials should be addressed to Y.W. (email: yzwang@zju.edu.cn) or to D.C. (email: chendh@ioz.ac.cn) or to C.H. (email: chuanhe@uchicago.edu).
} 
$\mathrm{D}$ ynamic DNA methylations expand the genetic code beyond the four canonical bases and carry important epigenetic information that can be transmitted among generations of cells or organisms ${ }^{1}$. DNA methylations such as $N^{4}$-methyldeoxylcytosine, 5-methyldeoxycytosine $\left(5 \mathrm{mC}\right.$ or $\left.\mathrm{m}^{5} \mathrm{dC}\right)$ and $N^{6}$-methyldeoxyadenosine $\left(6 \mathrm{~mA}\right.$ or $\left.\mathrm{m}^{6} \mathrm{dA}\right)$ are known to exist and carry functional roles in living organisms ${ }^{2}$. $N^{4}$-methyldeoxylcytosine and $6 \mathrm{~mA}$ are primarily used by prokaryotes in the restriction-modification system to protect their own genomes from foreign DNA invasion ${ }^{2}$, whereas $5 \mathrm{mC}$ is best known for its significant epigenetic roles in eukaryotes, especically in mammals and plants $\mathrm{s}^{3,4}$.

Although both $6 \mathrm{~mA}$ and $5 \mathrm{mC}$ were discovered almost at the same time a few decades ago, attention to $6 \mathrm{~mA}$ in eukaryotes has been limited mostly due to its low abundance in multicellular eukaryotes and technological limitations. In most cells and tissues of vetebrates including mammals, $6 \mathrm{~mA}$ is either detected at a few to tens p.p.m. (part per million A) level or simply not detectable at all using modern mass spectrometry technique ${ }^{5}$. The extremely low abundance of $6 \mathrm{~mA}$ in most organisms, at a level similar to DNA base damage, has cast in the past further doubt about the functional relevance of $6 \mathrm{~mA}$. Very recently, we and others reported the discovery/characterization of $6 \mathrm{~mA}$ in Chlamydomonas reinhardtii ${ }^{6}$, Caenorhabditis elegans ${ }^{7}$ and Drosophila $^{8}$, suggesting its potential epigenetic functions ${ }^{9,10}$. In C. reinhardtii, $6 \mathrm{~mA}$ was found to be located in the AT motif near the transcription start sites. It marks active genes and is associated with nucleosome positioning ${ }^{6}$. In the genomes of C. elegans and Drosophila, $6 \mathrm{~mA}$ affects trans-generational inheritance ${ }^{7}$ and expression of certain transposons ${ }^{8}$, respectively. Although we have been working on $6 \mathrm{~mA}$ in vertebrates and mammals, a recent publication has reported the detection of $6 \mathrm{~mA}$ in Xenopus laevis and mammals, albeit with very low levels of $6 \mathrm{~mA}$ observed $(0.00009 \%)^{11}$. A more recent work reported a potential $6 \mathrm{~mA}$ demethylase in mammals, which still needs to be validated with biochemical and physiological studies ${ }^{12}$. The $6 \mathrm{~mA}$ level reported is again quite low even after enrichment. This modification was found to be depleted in coding regions and might exist in the AG sequence content. In this work, we characterize DNA $6 \mathrm{~mA}$ modification in zebrafish and pig. We found that $6 \mathrm{~mA}$ accumulates to relatively high abundances during early embryogenesis $(6 \mathrm{~mA} / \mathrm{A}$ up to $\sim 0.1-0.2 \%$ ), but is attenuated to the background p.p.m. level with the development progression. During this process, a substantial set of $6 \mathrm{mAs}$ locate in repetitive regions of the genome.

\section{Results}

DNA 6mA modification during early embryogenesis of zebrafish. We have been searching biological processes during which $6 \mathrm{~mA}$ accumulates to relatively high abundance. We reason that an abundant accumulation and a dynamic change of $6 \mathrm{~mA}$ could indicate functional relevance. After quantifying $6 \mathrm{~mA}$ levels in various cell types and tissues, we noticed that $6 \mathrm{~mA}$ accumulates to surprisingly high levels during early embryogenesis in vertebrates such as zebrafish and pig. Using zebrafish as a model, we purified and quantified genomic DNAs (gDNAs) from sperm, oocyte, early embryos with different time point and adult fish organs by using a sensitive ultra-high-performance liquid chromatography coupled with a triple-quadrupole tandem mass spectrometry (UHPLC-QQQ-MS/MS) assay with pure $6 \mathrm{~mA}$ nucleoside as an external standard 6 . We devoted significant efforts to the collection of the oocytes and early embryos, to purify sufficient gDNA for LC-MS/MS measurements. On average, we collected over 10,000 cells at each embryo stage and purified gDNA.
The LC-MS/MS result shows that the sperm gDNA contains around $0.003 \%$ of $6 \mathrm{~mA} / \mathrm{A}$, whereas the oocyte contains fivefold higher $6 \mathrm{~mA}$ than in sperm. On zygote formation, the level of $6 \mathrm{~mA}$ increases and doubles that of oocyte. Interestingly, starting from the 1-cell zygote, the level of $6 \mathrm{~mA}$ in DNA further increases along with development and reaches a maximum of $\sim 0.1 \%$ $6 \mathrm{~mA} / \mathrm{A}$ at around 32-cell to 64-cell embryo stage corresponding to $\sim 2 \mathrm{~h}$ post fertilization ( $2 \mathrm{hpf}$; Fig. 1a and Supplementary Fig. 1a) ${ }^{13}$. Afterwards, the $6 \mathrm{~mA}$ level gradually decreases to around $0.006 \%$ at 512 -cell stage and stays at this low level till prim22 ( 36 hpf). We further characterized adult fish organs including the brain, eye, heart, ovary, testis, muscle and intestine; all of them yielded a relatively low ratio of $6 \mathrm{~mA} / \mathrm{A}$ at $0.002-0.004 \%$ (Supplementary Fig. 1b). Dot blot assay was used as an independent way to measure $6 \mathrm{~mA}$ levels at selected zebrafish early development stages (Supplementary Fig. 2), showing results consistent with LC-MS/MS experiments.

Immunostaining of $6 \mathrm{~mA}$ in zebrafish embryonic gDNAs. To exclude the possibility that the detected LC-MS/MS signal is due to foreign $6 \mathrm{~mA}$ contamination, we applied immunofluorescence staining of the embryos ${ }^{14}$ with anti-6mA-specific antibody (after treating with RNase A to digest and wash away all RNAs) for $6 \mathrm{~mA}$ detection in gDNA. Very weak fluorescence was observed from the sperm staining, while oocyte staining displayed stronger signals (Fig. $1 \mathrm{~b}$ and Supplementary Fig. 3a). Starting from the zygote stage, the nuclear immunofluorescence of embryos increases significantly along with the development, reaching its maximum at about 32-cell to 64-cell stage (Fig. 1b). Afterwards, the signal decreases with the progression of the development. These observations are consistent with the LC-MS/MS result. After treating with DNase, the immunofluorescence signal disappeared (Supplementary Fig. 3b). Together, LC-MS/MS, dot blot assay and immunostaining results confirm the existence of abundant $6 \mathrm{~mA}$ during early embryogenesis of zebrafish. Mammalian cells and tissues tend to contain a few percent of $5 \mathrm{mC}$ and $0.01-1 \%$ 5-hydroxymethycytosine (5hmC) in gDNA. Our observation of $6 \mathrm{~mA}$ during early embryogenesis represents the first example that an abundant $6 \mathrm{~mA}$ level comparable to those of $5 \mathrm{mC}$ and $5 \mathrm{hmC}$ is observed in vertebrates. The dynamic changes suggest functional roles of $6 \mathrm{~mA}$ during the process. To further substantiate this observation in mammals, we studied early embryogenesis in pig.

Quantification of DNA 6mA level in pig embryos. It is much harder to obtain sufficient pig oocytes and embryos. The current available way to obtain early embyros is done through in vitro fertilization followed by culturing into different embryonic stages $^{15}$; however, this method is restricted by low fertilization rates. Owing to the technical limitation, the successfully fertilized oocyte can only be cultured to, at most, the blastocyst stage. To have enough gDNA for LC-MS/MS and immuostaining experiments, we devoted significant efforts to collecting sufficient materials. Besides pig sperm and oocyte, we selected 4-cell, morula and blastocyst stages $(\sim 2,500$ oocytes, $\sim 1,8004 \mathrm{C}$ stage, $\sim 900$ morulae and $\sim 500$ blastocysts) and purified gDNAs for LC-MS/MS measurement (Fig. 1c). Similar to zebrafish, the $6 \mathrm{~mA} / \mathrm{A}$ ratio in oocyte $(0.09 \%)$ is approximately six times higher than that of sperm. This ratio rises to $\sim 0.17 \%$ from the four-cell to the morula stage and then decreases to $0.05 \%$ at the blastocyst stage. The corresponding immunostaining results are consistent with LC-MS/MS measurements (Fig. 1d and Supplementary Fig. 3c), which further supports the presence of abundant $6 \mathrm{~mA}$. We also checked the $6 \mathrm{~mA}$ level in 

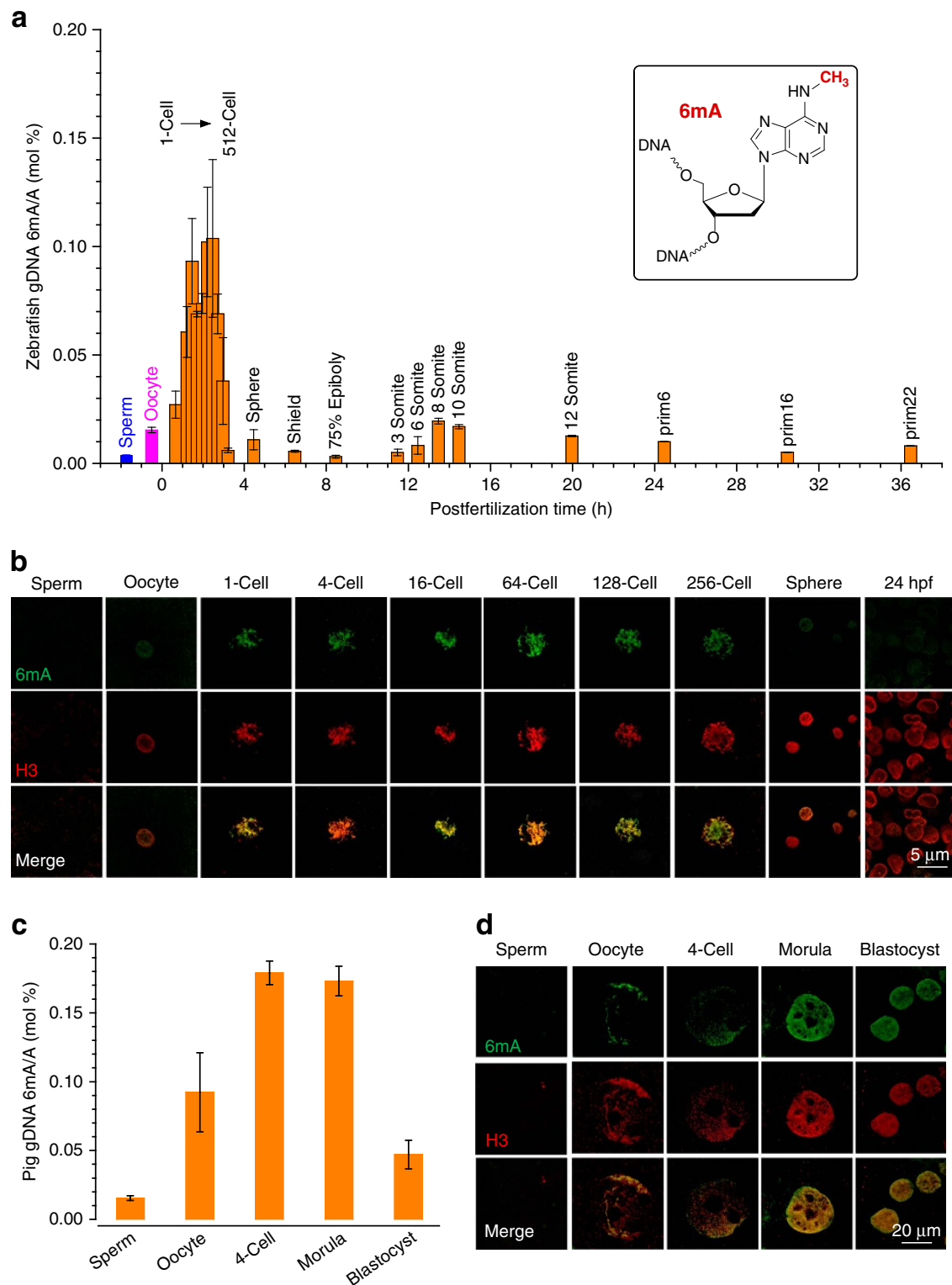

d

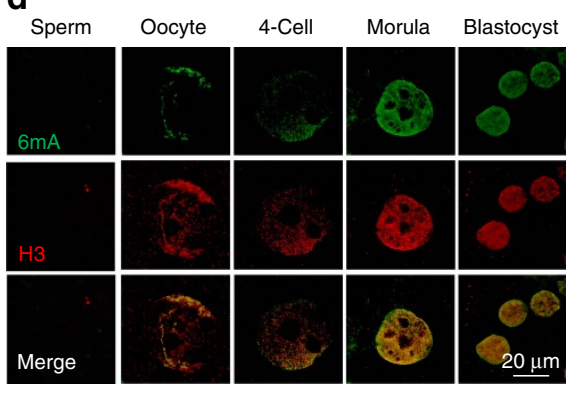

Figure 1 | $6 \mathrm{~mA}$ modification in gDNAs of gametes and selected early embryos in both zebrafish and pig (a,c) Quantification of $6 \mathrm{~mA}$ modification in isolated gDNA from sperm, oocyte and various embryo stages of zebrafish (a) and pig (c) by UHPLC-QQQ-MS/MS. The mole ratios of $6 \mathrm{~mA} / \mathrm{A}$ are shown, error bars indicate mean \pm s.d. $(n=3)$. (b,d) Immunofluorescence images of selected embryo stages of zebrafish $(\mathbf{b})$ and pig $(\mathbf{d})$ at single-cell level stained by anti-6mA antibody (green, rabbit polyclonal from SYSY) and anti-Histone 3 (H3) antibody (red, mouse monoclonal from Biodragon Immunotechnologies). Early embryo stages show strong fluorescence indicative of the high abundance of $6 \mathrm{~mA}$ in gDNA, whereas the signal is diminished with the progression of the embryo development. Full embryo images are presented in Supplementary Fig. 3.

the gDNAs of various adult pig tissues with only low p.p.m. level observed (Supplementary Fig. 1c).

Distribution of $6 \mathrm{~mA}$ in zebrafish embryonic gDNAs. Next, we studied the genomic distribution of $6 \mathrm{~mA}$ in selected systems. The antibody-based (SYSY 6mA antibody) immunoprecipitation of $6 \mathrm{~mA}$-containing DNA followed by next-generation high-throughput sequencing $(6 \mathrm{~mA}-\mathrm{IP}-\mathrm{seq})^{6}$ was used to map the genomic distribution patterns of $6 \mathrm{~mA}$. The $6 \mathrm{~mA}-\mathrm{IP}$-seq generally requires micrograms of gDNA because of the unavoidable loss of materials in many purification steps during the construction of sequencing libraries. A large number of embryos would be required, to obtain sufficient gDNA materials, in particular at the early stages. We collected 5,000 zebrafish embryos at the 64-cell stage $(\sim 1 \mu \mathrm{g}$ gDNA isolated) in which $6 \mathrm{~mA}$ accumulates to the highest level, as well as gDNAs from later stages including $11 \mathrm{hpf}, 12 \mathrm{hpf}$ and $13 \mathrm{hpf}$, and performed $6 \mathrm{~mA}-\mathrm{IP}$-seq. Owing to the difficulty of acquiring enough gDNA from pig embyros, we were unable to sequence pig samples at the current stage.

We performed bioinformatic analysis of the sequencing data generated from the zebrafish genome. By comparing $6 \mathrm{~mA}-\mathrm{IP}$ with input data, we identified $\sim 57,000$ to $\sim 3,300$ potential $6 \mathrm{~mA}$ peaks in samples of $64 \mathrm{C}, 11 \mathrm{hpf}, 12 \mathrm{hpf}$ and $13 \mathrm{hpf}$ (Supplementary Fig. 4a), among which the $64 \mathrm{C}$ samples possess the most peaks, consistent with the $6 \mathrm{~mA}$ abundance measurements. These samples show peak overlapping ratio of $41-50 \%$ across different time points (Supplementary Fig. 4b). In general, the $6 \mathrm{~mA}$ peaks are distributed widely across the genome with slight enrichment after transcription start site (TSS; Supplementary Fig. 5) and they were found to be enriched at exon, but not intron, intergenic nor 
promoter regions (Supplementary Fig. 6), which is different from the exon depletion case observed in the $X$. laevis testis genome ${ }^{11}$. Specifically, we found that $\sim 78-81 \%$ of the peaks locate in repetitive elements (REs), which suggests a close relationship between $6 \mathrm{~mA}$ and RE (Fig. 2a and Supplementary Fig. 7a). Interestingly, $6 \mathrm{~mA}$ peaks in the simple repeat region accounts for $37-45 \%$ of the total peaks. We further divided the RE regions into subtypes based on RepeatMasker ${ }^{16}$. Compared with the background constitution of RE regions in the genome, $6 \mathrm{~mA}$ peaks enriches in simple repeat, $\mathrm{RC} /$ Helitron (rolling-circle transposon), LTR (long terminal repeat retrotransposon), LINE/L1 (long interspersed element) and DNA/Maverick (virus-like DNA transposon) classes of REs (Fig. 2b), thus reinforcing the finding that $6 \mathrm{~mA}$ is correlated with REs. Sequencing of biological replicates at $11 \mathrm{hpf}, 12 \mathrm{hpf}$ and $13 \mathrm{hpf}$ stages revealed good consistency (Supplementary Figs 4 and $7 \mathrm{~b}$, and Supplementary Table 1).
Consensus motifs containing $6 \mathrm{~mA}$. To search for sequence preference of $6 \mathrm{~mA}$, we performed motif analysis on $6 \mathrm{~mA}$ peak regions. Considering the sequence diversity between $\mathrm{RE}$ and non-RE regions, we divided peaks to three groups: simple repeat regions, other $\mathrm{RE}$ regions apart from simple repeats and regions not related to $\mathrm{RE}$ (non-RE). Interestingly, we obtained significant but also diverse motifs for each group. For instance, at $64 \mathrm{C}$ stage the regions of simple repeat, other RE regions and non-RE are mainly featured with $5^{\prime}$-CACACACA- $3^{\prime}$, $5^{\prime}$-CCTAGC- $3^{\prime}$ and $5^{\prime}$-CAGCAG- $3^{\prime}$ motifs, respectively (Fig. 2c). Among the simple repeats, tandem CA motif is the most prevalent, which is followed by tandem $5^{\prime}$-TCCA- $3^{\prime}$ and $5^{\prime}$-CCAA- $3^{\prime}$ motifs. The most significant motif sequences showed recurrence in all sequencing samples (Supplementary Fig. 7c) and are different from those observed in a recent study ${ }^{11}$. a

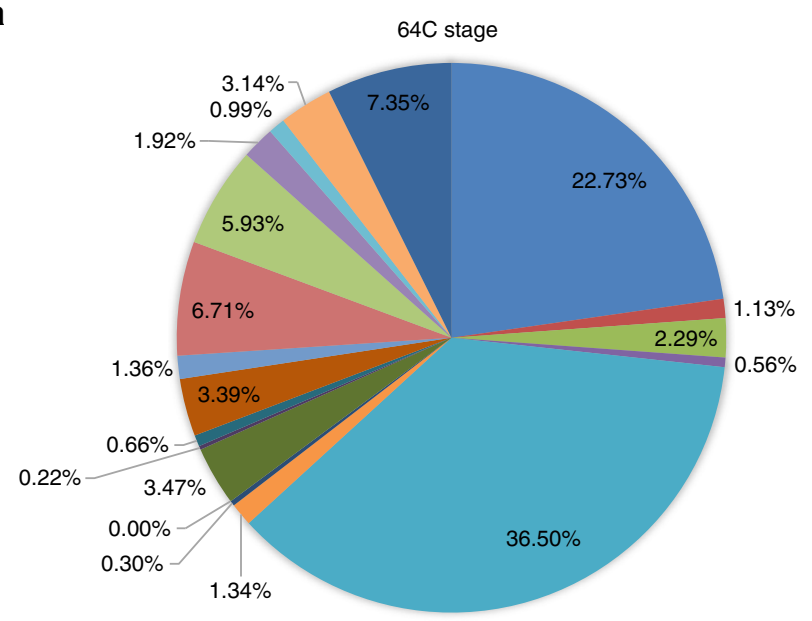

b

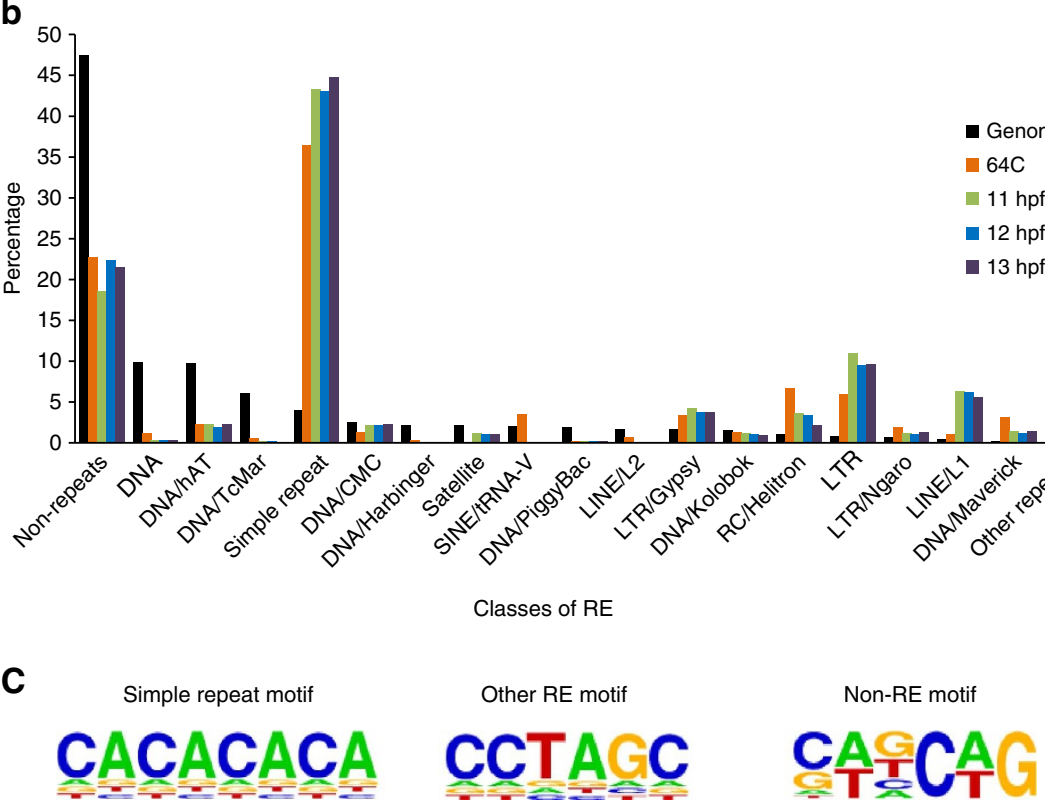

Figure 2 | DNA 6mA-IP-seq reveals the distribution of $6 \mathrm{~mA}$ across the genome of zebrafish at selected embryonic stages. (a) Pie chart showing the distribution of $6 \mathrm{~mA}$ peaks at 64-cell (64C) stage. The peaks located in REs are classified into subgroups based on RepeatMasker annotation. (b) $6 \mathrm{~mA}$ peak classification for samples of $64 \mathrm{C}, 11 \mathrm{hpf}, 12 \mathrm{hpf}$ and $13 \mathrm{hpf}$. The genome background distribution is shown for comparison. The peaks are classified with the same criteria shown in a. (c) Sequence motifs of $6 \mathrm{~mA}$ peaks in simple repeat, other REs apart from simple repeats (other RE) and non-repetitive regions (non-RE) for the 64C stage sample. Motifs were searched and generated by Homer software. The P-values for simple repeat, RE and non-RE motifs are $5 e-1163,1 e-1557$ and $1 e-390$, respectively. 
6mA-IP-seq by using different anti-6mA antibody. To avoid potential sequencing bias introduced by antibody, we chose another 6mA antibody (Abcam) to perfrom independent $6 \mathrm{~mA}-\mathrm{IP}$-seq for the $64 \mathrm{C}$ stage and found $6 \mathrm{~mA}$ distribution pattern and peak motif consistent with those described above by using the SYSY antibody (Supplementary Fig. 8). Simple repeat regions are again significantly enriched with $6 \mathrm{~mA}$, accounting for $\sim 53 \%$ peaks across the genome. These two antibodies show slightly different affinities to $6 \mathrm{~mA}$ with the Abcam antibody possessing a relatively lower affinity but slightly higher selectivity (Supplementary Fig. 9); the use of the Abcam antibody appears to further enrich $6 \mathrm{~mA}$-abundant DNA segments. This result further suggests that simple repeat region is more enriched with $6 \mathrm{~mA}$ modification.

Selected 6mA-containing targets. To probe the correlation between the expression of REs enriched with $6 \mathrm{~mA}$ and the timing of accumulation, we selected a few targets and used quantitative reverse transcription PCR to quantify their transcript expression levels at various developmental stages (Supplementary Fig. 10). Among the selected targets, Thy1 (LTR/Gypsy), Parp4 (LTR/Gypsy) and Hel1 (RC/Helitron) all showed a trend of reduced expression with the progression of development. These data suggest that the expression of REs might be positively correlated with the $6 \mathrm{~mA}$ abundance.

\section{Discussion}

$6 \mathrm{~mA}$ is a well-studied prokaryotic DNA marker. In Escherichia coli, $6 \mathrm{~mA}$ is present in the palindromic $5^{\prime}$-GATC- $3^{\prime}$ motif and participates in the control of chromosome replication, nucleoid segregation, mismatch repair and transcription regulation ${ }^{17} .6 \mathrm{~mA}$ is also present in eukaryotes and appears to have functional roles ${ }^{10}$. We show here that $6 \mathrm{~mA}$ can accumulate to $\sim 0.1-0.2 \%$ of $6 \mathrm{~mA} / \mathrm{A}$ during early embryogenesis in zebrafish and pig. Levels of $6 \mathrm{~mA}$ in oocyte are several folds higher than those of sperms (p.p.m. level) and, on zygote formation, the abundance of $6 \mathrm{~mA}$ increases $(6 \mathrm{~mA} /$ A up to $\sim 0.1-0.2 \%$ ) and then decreases (back to p.p.m. level) with the progression of embyronic development. $6 \mathrm{~mA}$ prefers to be enriched in REs, whose expression might be positively correlated with the $6 \mathrm{~mA}$ abundance. The highest abundance of $6 \mathrm{~mA}$ observed appoaches the level of $5 \mathrm{hmC}$ in most mammalian tissues. Future studies should reveal how $6 \mathrm{~mA}$ may correlate $5 \mathrm{mC}$ reprogramming in mammals ${ }^{18}$, the role of $6 \mathrm{~mA}$ in $\mathrm{REs}^{12}$ and other regions (with motifs such as $5^{\prime}$-CACACACA- $3^{\prime}, 5^{\prime}$-CCTAGC- $3^{\prime}$ and $5^{\prime}$-CAGCAG-3'), enzymes that install and/or erase $6 \mathrm{~mA}$ and potential 'reader' proteins that may bind $6 \mathrm{~mA}$ to mediate biological functions.

\section{Methods}

Zebrafish strains and husbandry. Zebrafish (Danio rerio) embryos were derived from the Tubingen zebrafish lines. Embryos were incubated in Holtfreter's solution at $28.5^{\circ} \mathrm{C}$

\footnotetext{
Collection of early embryos and isolation of their gDNAs. Unfertilized sperm were squeezed out of anaesthetized males and oocytes were squeezed out of anaesthetized females (the oocytes were activated when they were squeezed into Holtfreter's solution; the polar bodies were extruded from the egg surface following egg activation). The fertilized embryos were grown in Holtfreter's solution at $28.5^{\circ} \mathrm{C}$ and were staged according to standard morphological criteria. The oocytes and different stages of embryos were frozen in liquid nitrogen until enough embryos were collected for DNA extraction. For sperm, they were directly squeezed

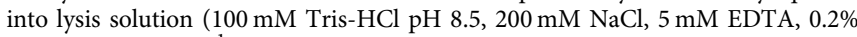
SDS and $50 \mu \mathrm{g} \mathrm{ml}^{-1}$ proteinase K) for gDNA extraction. For oocytes and early embryos, to each aliquot of 300 dechorionated embryos was added $600 \mu \mathrm{l}$ of lysis solution. The solution was incubated in a rotation oven at $55^{\circ} \mathrm{C}$ overnight. Equal volume of phenol/chloroform ( $\mathrm{pH} \mathrm{8.0)}$ was added for extraction and the mixture was vortexed briefly and spun for $10 \mathrm{~min}$ in a microfuge at $16,000 \mathrm{~g}$. To the collected aqueous solution $2 \mu \mathrm{l}$ of RNase $\mathrm{A}\left(10 \mathrm{mg} \mathrm{ml}^{-1}\right)$ was added and the
}

resultant solution was incubated in thermomixer at $37^{\circ} \mathrm{C}$ for additional $3 \mathrm{~h}$. Phenol/chloroform extraction and DNA precipitation with $1 / 10$ volume of $5 \mathrm{M}$ $\mathrm{NaCl}$ and 1 volume of isopropanol were performed. The obtained DNA pellet was dissolved with $3 \mathrm{dH}_{2} \mathrm{O}$.

Pig oocyte collection and in vitro maturation. Ovaries of prepubertal gilts were collected in a local abattoir and transported to the laboratory at $37^{\circ} \mathrm{C}$ in a $0.9 \%$ $\mathrm{NaCl}$ solution supplemented with kanamycin and penicillin at $30-35^{\circ} \mathrm{C}$ within $3 \mathrm{~h}$. Antral follicles of 3-6 mm were aspirated to collect the cumulus-oocyte complex (COCs) using a syringe. After washing three times with PVA-TL-HEPES media, the oocyte selection started with a screening for those oocytes that had a multilayered compact cumulus and a homogeneous ooplasm. The oocytes were washed twice again with TCM-199 media, which had been equilibrated for $3 \mathrm{~h}$ at $38.5{ }^{\circ} \mathrm{C}$ under $5 \% \mathrm{CO}_{2}$. Subsequently, the COCs were matured in TCM- 199 media without hormones at $38.5^{\circ} \mathrm{C}$ in a humidified atmosphere of $5 \% \mathrm{CO}_{2}$ for $42-44 \mathrm{~h}$. Then, the COCs were washed in the working solution $(0.03 \mathrm{~g}$ hyaluronidase, $5.46 \mathrm{~g}$ mannitol, $0.001 \mathrm{~g}$ BSA, $5 \mathrm{ml}$ PVA-TL-HEPES and $95 \mathrm{ml}$ $\mathrm{ddH}_{2} \mathrm{O}$ ) to remove the cumulus cell and the mature oocytes were picked out for storage at $-80^{\circ} \mathrm{C}$

In vitro fertilization. After maturation, the COCs were washed gently with $2 \mathrm{ml}$ fresh IVF medium, to remove cumulus cells. After washing, denuded oocytes were placed in $50 \mu \mathrm{l}$ drops of IVF medium covered with mineral oil. The oocytes were incubated at $38.5^{\circ} \mathrm{C}$ in an atmosphere of $5 \% \mathrm{CO}_{2}$ for $30 \mathrm{~min}$ until the spermatozoa were added. The sperms were washed twice by DPBS $(136.89 \mathrm{mM} \mathrm{NaCl}, 2.68 \mathrm{mM}$ $\mathrm{KCl}, 8.1 \mathrm{mM} \mathrm{Na}_{2} \mathrm{HPO}_{4}$ and $1.46 \mathrm{mM} \mathrm{CaCl}_{2} \cdot 2 \mathrm{H}_{2} \mathrm{O}$ ) at $12,000 \mathrm{~g} \mathrm{~min}^{-1}$ for $30 \mathrm{~s}$ and the resulting pellet was suspended in the IVF medium. After appropriate dilution, $50 \mu \mathrm{l}$ of this sperm suspension was added to a $50 \mu \mathrm{l}$ drop of IVF medium containing the oocytes at an oocytes:spermatozoa ratio of 1:4,000. The oocytes were incubated with the spermatozoa in IVF medium for $6 \mathrm{~h}$ at $38.5^{\circ} \mathrm{C}$ under $5 \% \mathrm{CO}_{2}$ Next, they were transferred into $500 \mu \mathrm{l}$ PZM-3 medium and cultured for another 2 days to the 4 -cells stage, 4 days to the morula stage and 7 days to the blastocyst stage, and the samples were stored at $-80^{\circ} \mathrm{C}$ for further assays.

Mediums used in pig oocyte maturation and fertilization. The related medium recipes are shown as follows.

PVA-TL-HEPES: $6.663 \mathrm{~g} \mathrm{NaCl}$ (Sigma-S-5886), $0.239 \mathrm{~g} \mathrm{KCl}$ (Sigma, P4504), $0.168 \mathrm{~g} \mathrm{NaHCO}_{3}$ (Sigma, S8875), $0.041 \mathrm{~g} \mathrm{NaH}_{2} \mathrm{PO}_{4}$ (Sigma, S5011), $0.102 \mathrm{~g}$ $\mathrm{MgCl}_{2} \cdot 6 \mathrm{H}_{2} \mathrm{O}$ (Sigma, M0250), 2.383 g HEPES (Sigma, H3784), $0.065 \mathrm{~g}$ penicillin (Sigma, P3032), $0.010 \mathrm{~g}$ Phenol Red (Sigma, 5,530), $0.294 \mathrm{~g} \mathrm{CaCl}_{2} .2 \mathrm{H}_{2} \mathrm{O}$ (Sigma,C7902), $0.1 \mathrm{~g}$ polyvinyl alcohol (PVA, Sigma, P8136), 2.186 g sorbitol (Sigma, S1876), 0.025 g Gentamicin (Gibco, 15710-064), $0.022 \mathrm{~g}$ sodium pyruvate (Sigma, P4562), $998 \mathrm{ml}$ Milli Q $\mathrm{H}_{2} \mathrm{O}$ and $1.868 \mathrm{ml} \mathrm{Na}$ Lactate (Sigma, L7900), adjusting $\mathrm{pH}$ to $7.2-7.4$ and osmotic pressure to $295-310$ mOsm.

TCM-199: $3.05 \mathrm{mM}$ D-glucose (Sigma, G7021), $0.91 \mathrm{mM}$ sodium pyruvate (Sigma, P4562), 0.1\% PVA (Sigma, P8136), $75 \mu \mathrm{g} \mathrm{ml}^{-1}$ penicillin (Sigma, P3032), $50 \mu \mathrm{g} \mathrm{ml}^{-1}$ streptomycin (Sigma, S1277), $0.5 \mu \mathrm{g} \mathrm{ml}^{-1}$ luteinizing hormone (Sigma, L5269), $10 \mathrm{ng} \mathrm{ml}^{-1}$ epidermal growth factor (Sigma, S4127), $0.5 \mu \mathrm{g} \mathrm{ml}^{-1}$ follicle stimulating hormone (Sigma, F2293), $0.57 \mathrm{mM}$ cysteine (Sigma, C8152) and $10 \%$ porcine follicular fluid.

IVF medium (mTBM): $113.1 \mathrm{mmoll}^{-1} \mathrm{NaCl}, 3.0 \mathrm{mmoll}^{-1} \mathrm{KCl}, 7.5 \mathrm{mmoll}^{-1}$ $\mathrm{CaCl}_{2} \cdot 2 \mathrm{H}_{2} \mathrm{O}, 20 \mathrm{mmoll}^{-1}$ Tris, $11 \mathrm{mmoll}^{-1}$ glucose, $5 \mathrm{mmoll}^{-1}$ sodium pyruvate, $1 \mathrm{mmoll}^{-1}$ caffeine and $0.1 \%$ BSA into the $0.2 \mathrm{ml}$ spermatozoa.

PZM-3 medium: $108 \mathrm{mM} \mathrm{NaCl}$ (Sigma, S-5886), $10 \mathrm{mM} \mathrm{KCl} \mathrm{(Sigma,} \mathrm{P-4504),}$ $0.35 \mathrm{mM} \mathrm{KH}_{2} \mathrm{PO}_{4}$ (Sigma, P-5655), $0.40 \mathrm{mM} \mathrm{MgSO}_{4} .7 \mathrm{H}_{2} \mathrm{O}$ (Sigma, M-1880), $25.07 \mathrm{mM} \mathrm{NaHCO}_{3}$ (Sigma, S-8875), $0.2 \mathrm{mM}$ sodium pyruvate (Sigma, 4,562) and $2.00 \mathrm{mM} \mathrm{Ca}(\text { Lactate) })_{2} .5 \mathrm{H}_{2} \mathrm{O}$ (Fisher, $\left.\mathrm{C} 100-500\right), 1.00 \mathrm{mM} \mathrm{L}$-glutamine (Sigma, G-7029), $5.00 \mathrm{mM}$ hypotaurine (Sigma, H-1384), $10 \mathrm{mll}^{-1}$ NEAA (Sigma, M7145), $20 \mathrm{mg} \mathrm{ml}^{-1}$ EAA (Sigma, B-6766), $0.05 \mathrm{mg} \mathrm{ml}^{-1}$ gentamicin and $3 \mathrm{mg} \mathrm{ml}^{-1}$ BSA (Sigma, A-0281).

\section{Quantification of 6mA in GDNA by UHPLC-QQQ-MS/MS. Zebrafish} embryonic gDNA $(20-300 \mathrm{ng})$ or tissue gDNA $(1-2 \mu \mathrm{g})$ in $26 \mu \mathrm{l}$ of nuclease-free $\mathrm{H}_{2} \mathrm{O}$ was denatured at $100^{\circ} \mathrm{C}$ for $5 \mathrm{~min}$, chilled on ice for $2 \mathrm{~min}$ and digested by $1 \mu \mathrm{l}$ nuclease $\mathrm{P} 1\left(1 \mathrm{U} \mu \mathrm{l}^{-1}\right.$, Wako USA, 145-08221) in $10 \mathrm{mM} \mathrm{NH}_{4} \mathrm{OAc} \mathrm{pH} 5.3$ (adding $3 \mu \mathrm{l} 100 \mathrm{mM} \mathrm{NH}_{4} \mathrm{OAc}$ ) at $42{ }^{\circ} \mathrm{C}$ overnight. This process was followed with the addition of $3.4 \mu \mathrm{l} \mathrm{NH}_{4} \mathrm{HCO}_{3}(1 \mathrm{M})$ and $1 \mu \mathrm{l}$ of phosphodiesterase I from crotalus adamanteus venom $(0.001 \mathrm{U}$, Sigma, $\mathrm{P} 3243-1 \mathrm{VL})$ at $37^{\circ} \mathrm{C}$ for $2 \mathrm{~h}$ and finally by addition of $1 \mathrm{U}$ of alkaline phosphatase from E. coli (Sigma, P5931500UN) at $37^{\circ} \mathrm{C}$ for $2 \mathrm{~h}$. Digested DNA was diluted twofold with nuclease-free $\mathrm{H}_{2} \mathrm{O}$ and was filtered through $0.22 \mu \mathrm{m}$ filter (Millipore, SLGVR04NL). A portion of $10 \mu \mathrm{l}$ sample was injected into LC-MS/MS and the nucleosides were separated by reverse-phase UHPLC on a C18 column (Agilent, 927,700-092), with online MS detection using Agilent 6,460 QQQ-MS/MS set to multiple reaction monitoring in positive electrospray ionization mode. Nucleosides were quantified using the nucleoside precursor ion to base ion mass transitions of $266.1-150.0$ for $6 \mathrm{~mA}$ and 252.1 - 136.0 for A. Quantification of the ratio $6 \mathrm{~mA} / \mathrm{A}$ was performed using the calibration curves obtained from nucleoside standards running at the same time. 
Antibodies. For regular 6mA-IP-seq, the following two rabbit polyclonal anti-6mA antibodies were used: Synaptic Systems (SYSY), 202,003 and Abcam, ab151,230. For immunostaining experiments, rabbit 6mA antibody (SYSY, 202,003) and mouse monoclonal Histone 3 (H3) antibody (Beijing Biodragon Immunotechnologies, B1055F) were used.

Immunostaining and confocal imaging. For $6 \mathrm{~mA}$ immunostaining, the zebrafish embryos were fixed in $4 \%$ paraformaldehyde at $4{ }^{\circ} \mathrm{C}$ overnight. Afterwards, the embryos were dechorionated manually and dehydrated with methanol and rehydrated with PBS, and the embryos were permeabilized for 15 min with PBS containing $1 \%$ Triton X-100. The permeabilized embryos were denatured with $2 \mathrm{M}$ $\mathrm{HCl}$ for $1 \mathrm{~h}$ and then neutralized with $100 \mathrm{mM}$ Tris- $\mathrm{HCl}(\mathrm{pH} 8.5)$ for $20 \mathrm{~min}$. The embryos were washed and then incubated for $1 \mathrm{~h}$ with blocking buffer $(1.5 \%$ BSA in PBS containing $0.3 \%$ Tween and $50 \mu \mathrm{g} \mu \mathrm{ml}^{-1}$ RNase A for RNA digestion). After that, the embryos were incubated with $6 \mathrm{~mA}$ antibody $(1: 1,000$, SYSY antibody) at $4{ }^{\circ} \mathrm{C}$ overnight. Washed thrice with PBS, the embryos were incubated with the secondary antibody at a 1:2,000 dilution (goat anti-rabbit Alexa488, Molecular Probes). Images were acquired using Nikon software on a Nikon Eclipse TI microscopy.

For pig sperm, oocyte and embryo immunostaining, the published protocol was followed ${ }^{19}$. The gametes and embryos were washed with PBS, fixed with $4 \%$ paraformaldehyde in PBS for $15 \mathrm{~min}$, and permeabilized with $0.1 \%$ Triton $\mathrm{X}-100$ in PBS at room temperature for $15 \mathrm{~min}$. The permeabilized gametes and embryos were incubated in $4 \mathrm{~N} \mathrm{HCl}$ solution at room temperature for $15 \mathrm{~min}$ and followed by neutralization in $100 \mathrm{mM}$ Tris- $\mathrm{Cl}, \mathrm{pH} 8.0$ for $30 \mathrm{~min}$. After blocking and incubation overnight with anti-6mA antibody, they were washed and incubated with secondary antibody. Nuclei were stained with DAPI. Immunofluorescence was visualized using confocal laser scanning microscope.

6mA dot blot assay. The DNA were denatured by heating at $98^{\circ} \mathrm{C}$ for $10 \mathrm{~min}$ and spotted on nitrocellulose membranes (GE Healthcare, catalogue number RPN303B). The membrane was baked at $80^{\circ} \mathrm{C}$ for $1 \mathrm{~h}$ and cross-linked by ultraviolet irradiation, the membrane was blocked in 5\% BSA in PBS containing $0.5 \%$ Tween 20 (PBST) for $1.5 \mathrm{~h}$ at room temperature and then incubated with a $1: 10,000$ dilution of $6 \mathrm{~mA}$ antibody (SYSY) overnight at $4{ }^{\circ} \mathrm{C}$ After three washes with PBST, the membrane was incubated with a 1:5,000 dilution of horseradish peroxidase-conjugated anti-rabbit secondary antibody. The membrane was then washed with PBST and treated with enhanced chemiluminescence (ECL).

To estimate the level of $6 \mathrm{~mA}$ in zebrafish gDNA at different stages, synthetic $6 \mathrm{~mA}$-containing DNA oligonucleotide was diluted with unmethylated oligonucleotide to generate standards with a gradient of $6 \mathrm{~mA}$ content $(0.2,0.1,0.05,0.025,0.0125$ and $0.00625 \%)$. All the samples and standards were loaded at the same amount. Among the samples we tested, gDNAs at 64-cell, 256 -cell, sphere, $13 \mathrm{hpf}$ and $24 \mathrm{hpf}$ stages have $6 \mathrm{~mA}$ levels of around $0.05,0.01$, $0.004,0.002$ and $0.002 \%$, respectively, which is well consistent with the LC-MS/MS observation.

$6 \mathrm{~mA}$-containing DNA oligo:

5'-TTGCT(6mA)GGTGGTTGCT(6mA)GGCGGTTGCT(6mA)GGGT-3'

DNA 6mA-IP-seq and bioinformatic analysis. The published protocol of DNA $6 \mathrm{~mA}$-IP-seq was applied ${ }^{6}$. Fifty-basepair single-end sequencing was performed on the Illumina HiSeq2500 platform. Raw sequence reads were mapped to reference genomes (zv10/danRer10 for zebrafish) using Bowtie v1.0.1 (ref. 20), with parameters $-\mathrm{M} 1$, which randomly select one best match if multiple alignments were found. Then MACS ${ }^{21}$ software was used to identify the enriched regions ( $6 \mathrm{~mA}$ peaks) by comparing reads from the IP sample with that from the input sample. False discovery rate cutoff was set to 0.01 , to select statistically significant peaks. After these peak regions were obtained, the genomic loci were compared with the coordinates of repeat elements downloaded from RepeatMasker database $^{22}$. If more than half length of one peak region overlaps with one annotated repeat element, the peak was annotated as a repeat-originated peak. Gene annotation information was downloaded from UCSC database (http://hgdownload.soe.ucsc.edu/goldenPath/danRer10/database/). The enrichment of peaks distributed in each genomic region was calculated by HOMER (Hypergeometric Optimization of Motif EnRichment) software ${ }^{23}$.

Primers for 6mA-containing REs. See Supplementary Fig. 10.

Thyl-F: 5'-ACCTTCACTCCAGCTCCAGA-3'

Thy1-R: $5^{\prime}$-GTGCGGCAGTCTGTCTGATA-3' Parp4-F: 5'-ATCGTGCTCGTCCTCTCAGT- $3^{\prime}$ Parp4-R: $5^{\prime}$-CGGTTTGACCAAAAGCAAAT- ${ }^{\prime}$ Hell-F: $5^{\prime}$-CAACGACTGCAAGGTGAAGA-3' Hel1-R: 5'-GGGATTGGAACAACTCCAGA-3'.

Ethics statement. All animal studies were conducted in strict accordance with the recommendations in the Guide for the Care and Use of Laboratory Animals of the
Ministry of Science and Technology of the People's Republic of China. The protocols for zebrafish studies were approved by the Committee on the Ethics of Animal Experiments of the Institute of Zoology, Chinese Academy of Sciences (approval number: IOZ15001). The protocols for pig studies were approved by the Committee on Animal Care and Use and the Committee on the Ethics of Anima Experiments of Zhejiang University.

Data availability. The data that support the findings of this study are available from the corresponding author upon request.

\section{References}

1. Bird, A. Perceptions of epigenetics. Nature 447, 396-398 (2007).

2. Wion, D. \& Casadesus, J. N6-methyl-adenine: an epigenetic signal for DNA-protein interactions. Nat. Rev. Microbiol. 4, 183-192 (2006).

3. Law, J. A. \& Jacobsen, S. E. Establishing, maintaining and modifying DNA methylation patterns in plants and animals. Nat. Rev. Genet. 11, 204-220 (2010).

4. Smith, Z. D. \& Meissner, A. DNA methylation: roles in mammalian development. Nat. Rev. Genet. 14, 204-220 (2013).

5. Ratel, D., Ravanat, J.-L., Berger, F. \& Wion, D. N6-methyladenine: the other methylated base of DNA. BioEssays 28, 309-315 (2006).

6. Fu, Y. et al. $N^{6}$-Methyldeoxyadenosine marks active transcription start sites in Chlamydomonas. Cell 161, 879-892 (2015).

7. Greer, E. L. et al. DNA methylation on N6-adenine in C. elegans. Cell 161, 868-878 (2015)

8. Zhang, G. et al. $N^{6}$-Methyladenine DNA modification in Drosophila. Cell $\mathbf{1 6 1}$ 893-906 (2015).

9. Heyn, H. \& Esteller, M. An adenine code for DNA: a second life for $N^{6}$-methyladenine. Cell 161, 710-713 (2015)

10. Luo, G.-Z., Blanco, M. A., Greer, E. L., He, C. \& Shi, Y. DNA $N^{6}$-methyladenine: a new epigenetic mark in eukaryotes? Nat. Rev. Mol. Cell. Biol. 16, 705-710 (2015).

11. Koziol, M. J. et al. Identification of methylated deoxyadenosines in vertebrates reveals diversity in DNA modifications. Nat. Struct. Mol. Biol. 23, 24-30 (2015).

12. Wu, T. P. et al. DNA methylation on $N^{6}$-adenine in mammalian embryonic stem cells. Nature 532, 329-333 (2016).

13. Kimmel, C. B., Ballard, W. W., Kimmel, S. R., Ullmann, B. \& Schilling, T. F. Stages of embryonic development of the zebrafish. Dev. Dyn. 203, 253-310 (1995).

14. Wu, D. et al. Uracil-DNA glycosylase is involved in DNA demethylation and required for embryonic development in the zebrafish embryo. J. Biol. Chem. 289, 15463-15473 (2014).

15. Abeydeera, L. R., Wang, W. H., Prather, R. S. \& Day, B. N. Maturation in vitro of pig oocytes in protein-free culture media: fertilization and subsequent embryo development in vitro. Biol. Reprod. 58, 1316-1320 (1998).

16. Jurka, J. et al. Repbase update, a database of eukaryotic repetitive elements. Cytogenet. Genome Res. 110, 462-467 (2005).

17. Touzain, F., Petit, M.-A., Schbath, S. \& Karoui, M. E. DNA motifs that sculpt the bacterial chromosome. Nat. Rev. Microbiol. 9, 15-26 (2011).

18. Feng, S., Jacobsen, S. E. \& Reik, W. Epigenetic reprogramming in plant and animal development. Science 330, 622-627 (2010).

19. Nakamura, T. et al. PGC7 binds histone H3K9me2 to protect against conversion of $5 \mathrm{mC}$ to $5 \mathrm{hmC}$ in early embryos. Nature 486, 415-419 (2012).

20. Langmead, B., Trapnell, C., Pop, M. \& Salzberg, S. L. Ultrafast and memory-efficient alignment of short DNA sequences to the human genome. Genome Biol. 10, R25-R25 (2009).

21. Zhang, Y. et al. Model-based analysis of ChIP-Seq (MACS). Genome Biol. 9, R137-R137 (2008).

22. Bergman, C. M. \& Quesneville, H. Discovering and detecting transposable elements in genome sequences. Brief. Bioinform. 8, 382-392 (2007).

23. Heinz, S. et al. Simple combinations of lineage-determining transcription factors prime cis-regulatory elements required for macrophage and B cell identities. Mol. Cell 38, 576-589 (2010).

\section{Acknowledgements}

This study was supported by National Institutes of Health (HG006827), National Basic Research Program of China (2013CB945002 and 2012CB124705), Natural Science Foundation of China (31590831) and the Special Fund for Cultivation and Breeding of New Transgenic Organism (No. 2014ZX0800949B) of Ministry of Agriculture of China A part of this work was funded by the Chicago Biomedical Consortium with support from the Searle Funds at The Chicago Community Trust (to G.-Z.L. and C.H.). J.L. thanks the Thousand Young Talents Plan of China and Hundred Talents Program of Zhejiang University. We thank Dr P. Faber for helping with high-throughput sequencing 
experiments and S.F. Reichard, MA, for editing the manuscript. C.H. is an investigator of the Howard Hughes Medical Institute.

\section{Author contributions}

C.H. and J.L. conceived the project. J.L. and Y.Z. designed and performed most experiments. Y.Z. collected all the zebrafish embryos and isolated the gDNAs. Z.L. performed high-throughput sequencing data analyses. D.H. helped on the initial sequencing data analysis. Y.Y., K.C., H.Y. and Y.F. helped perform the construction of sequencing libraries. X.W. and X.Z. collected pig sperm, oocyte and embryo, and isolated their gDNAs. Y.W., D.C. and C.H. supervised the project. J.L. and C.H. wrote the manuscript. All the authors commented on the manuscript.

\section{Additional information}

Accession codes: The high-throughput data used in this study are deposited in the NCBI GEO database with accession number GSE76740.

Supplementary Information accompanies this paper at http://www.nature.com/ naturecommunications
Competing financial interests: The authors declare no competing financial interests.

Reprints and permission information is available online at http://npg.nature.com/ reprintsandpermissions/

How to cite this article: Liu, J. et al. Abundant DNA 6mA methylation during early embryogenesis of zebrafish and pig. Nat. Commun. 7, 13052 doi: 10.1038/ncomms13052 (2016).

\section{(c) (i)}

This work is licensed under a Creative Commons Attribution 4.0 International License. The images or other third party material in this article are included in the article's Creative Commons license, unless indicated otherwise in the credit line; if the material is not included under the Creative Commons license, users will need to obtain permission from the license holder to reproduce the material. To view a copy of this license, visit http://creativecommons.org/licenses/by/4.0/

(C) The Author(s) 2016 